\title{
ZnO: PVP Quantum Dot Ethanol Sensor
}

\author{
Madhuchhanda Choudhury ${ }^{1}$, Siddhartha Sankar Nath ${ }^{2 *}$, Rajarshi Krishna Nath ${ }^{3}$ \\ ${ }^{1}$ Department of Elec \\ tronics Communication, NIT Silchar, Silchar-10, Assam, India \\ ${ }^{2}$ Department of Physics \& Central Instrumentation Laboratory, Assam University, Silchar-12, Assam, India \\ ${ }^{3}$ Department of Physics, NIT Agartalar, Agartala, India \\ E-mail: "nathss08@gmail.com \\ Received June 30, 2011; revised July 21, 2011; accepted July 29, 2011
}

\begin{abstract}
We prepare of $\mathrm{ZnO}$ quantum dots embedded in polyvinylpyrrolidone (PVP) matrix and report it's working as ethanol sensor. The samples have been prepared via quenching technique where bulk $\mathrm{ZnO}$ powder is calcined at very high temperature of $1200^{\circ} \mathrm{C}$ and then quenched into ice cold polyvinylpyrrolidone solution. Thee acteiut the samples specimen have been characterized by using UV/VIS spectroscopy, X-ray diffracttion study and high resolution transmission electron microscopy (HRTEM). These studies indicate the sizes of quantum dots to be within $10 \mathrm{~nm}$. The prepared quantum dot samples have been examined for ethanol vapour sensing by exploring the variation of their resistance with time at different operating temperatures. It has been revealed that $\mathrm{ZnO}$ quantum dots can sense ethanol at low operating $\left(230^{\circ} \mathrm{C}\right)$ temperature with less response time.
\end{abstract}

Keywords: Quantum Dot, Ethanol, Sensor, Polyvinylpyrrolidone, Quenching

\section{Introduction}

Synthesis of semiconductor quantum dots and their different applications as various electronic and optoelectronic devices including different kinds of sensors are the frontier research areas at present [1-6]. Recently, many techniques [1-4] like molecular beam epitaxy (MBE), radio frequency sputtering (RF), liquid phase epitaxy (LPE), quenching etc. have been adopted to synthesize semiconductor quantum dots. But due to manifold advantages [3,6] viz. like simplicity, low cost, etc. quenching method draws the interest of recent researchers. In the present investigation, we discuss preparation of $\mathrm{ZnO}$ quantum dots on polyvinylpyrrolidone (PVP) matrix (which embeds the quantum dots) by quenching method and their ethanol vapour sensing behaviour which is a new and original work. The advantage of PVP over other polymer matrices viz. SBR latex matrix is that circular and uniformed quantum dots can be fabricated on PVP. The Prepared samples have been examined by different characterizing methods to reveal their nano natures [2]. These studies infer the formation of quantum dots within the dimension of $10 \mathrm{~nm}$. Next, ethanol sensing property of $\mathrm{ZnO}$ sample (i.e. $\mathrm{ZnO}$ quantum dots embedded in PVP) has been examined by exploring the variation of sample resistance with time in presence of ethanol vapour [7]. Vapour sensing property of semiconductor is purely a surface phenomenon [7-19]. That is why low dimensional specimen possessing large surface area are suitable for this purpose. Earlier, gas sensing of $\mathrm{ZnO}$ microstructure has been reported where the sensing starts at $300^{\circ} \mathrm{C}$ [13]. In earlier works, it has been revealed that ethanol sensitivityin in semiconductor microstructures increases with higher doping concentration of impurity like cobalt $[17,19]$. In the present work, it has been experimentally observed that undoped $\mathrm{ZnO}$ quantum dots embedded in PVP matrix can act as ethanol sensor with lower operating temperature $\left(230^{\circ} \mathrm{C}\right)$, with less response and recovery time. Thus, testing of $\mathrm{ZnO}$ quantum dots for ethanol sensing, which has not been focused in any report earlier, is interesting, and technically very important.

\section{Materials and Method}

To synthesize [3] $\mathrm{ZnO}$ quantum dots by quenching method, 3 gms of $\mathrm{ZnO}$ powder (99.99\% pure, E Merck) is calcined at $\sim 1200^{\circ} \mathrm{C}$ for 10 hours and then quenched into $4 \mathrm{wt} \%$ aqueous solution of polyvinylpyrrolidone (PVP) matrix (99.9\% pure, E Merck) kept at ice cold tempera- 
ture followed by its moderate stirring ( $175 \mathrm{rpm}$ ) for 30 minutes. This solution contains $\mathrm{ZnO}$ quantum dots embedded in polyvinylpyrrolidone. The film is developed on the laboratory glass slides by placing a few drops of $\mathrm{ZnO}$ quantum dot solution (embedded in PVP) on a clean slide and stretching over it by another clean slide.

\subsection{Result and Discussion}

$\mathrm{ZnO}$ specimen has been characterized by UV/VIS optical absorption spectroscopy (Perkin Elmer Lamda 35 1.24), $\mathrm{X}$-ray diffraction study (Bruker AXS, X-ray source: Cu $\mathrm{K}_{\alpha}$ ) and high resolution transmission electron microscopy (HRTEM) (JEM 1000 C XII). Optical absorption spectroscopy [6] shows sharp blue shifted absorption edge of the prepared samples with respect to that of bulk (Figure 1). Blue shift is a distinct signature of quantum dot formation [1,3,4] (Figure 1). By considering shifted absorption edge (at $210 \mathrm{~nm}$ ) of $\mathrm{ZnO}$ sample, average crystallite (particle) size has been estimated and found to be $10 \mathrm{~nm}$ by using the following hyperbolic band model [5].

$$
R=\sqrt{\frac{2 \pi^{2} h^{2} E_{g b}}{m^{*}\left(E_{g n}^{2}-E_{g b}^{2}\right)}}
$$

where $R$ is quantum dot radius ( $2 R$ is the diameter and hence the particle size), $E_{g b}$ is the bulk band gap, $E_{g n}$ is quantum dot band gap (calculated from the sharp absorption edge which is $210 \mathrm{~nm}$ as shown in Figure 2), $h$ is Planck's constant, $m^{*}$ is effective mass $\left(29.15 \times 10^{-31} \mathrm{~kg}\right.$ for $\mathrm{ZnO}$ ).

Similarly, from X-ray diffraction study (Figure 2) average particle size (crystallite size) is calculated by using Debye-Scherrer formula [2] $D=\frac{0.9 \lambda}{W \cos \theta}$, “ $\lambda$ ” is wave

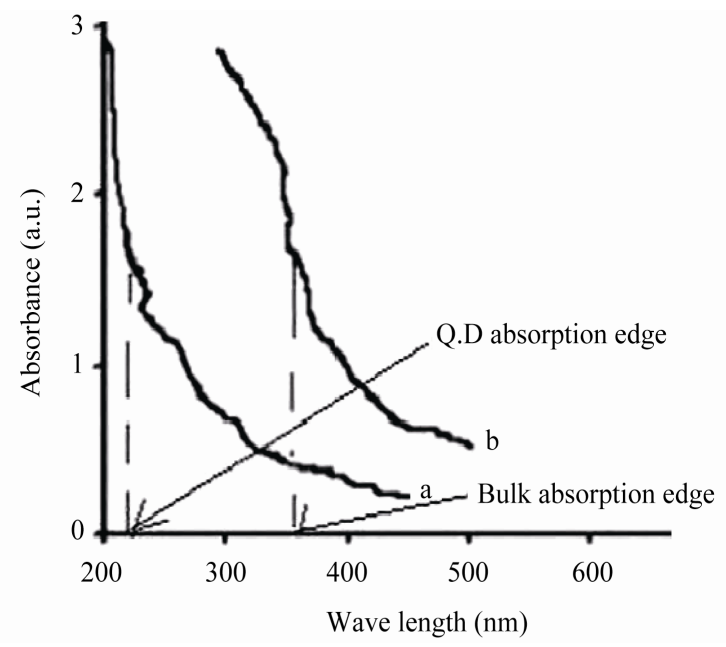

Figure 1. UV/VIS absorption spectra. (a) Q.D; (b) bilk.

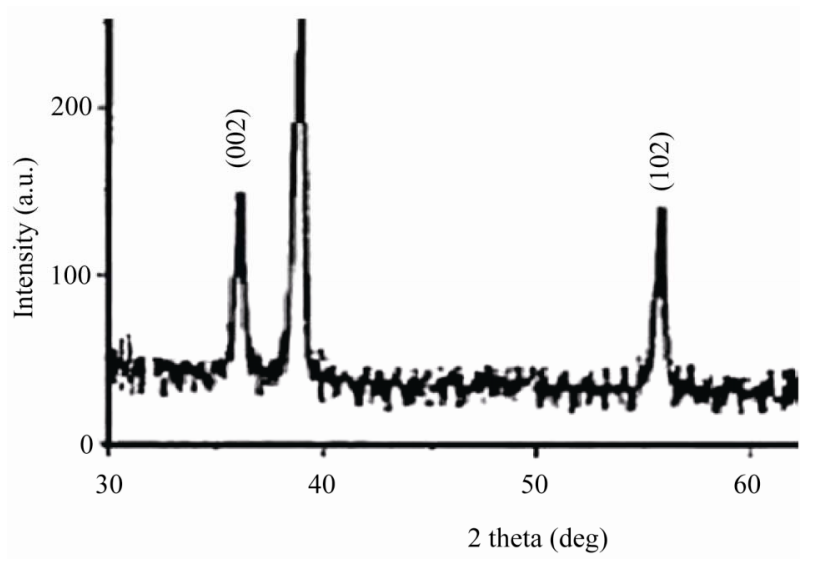

Figure 2. XRD Spectra of ZnO quantum dots.

length of X-ray (0.1541 nm), “ $W$ ” is FWHM (full width at half maxima), “ $\theta$ ' (theta) is the glancing angle and “ $D$ ” is particle diameter (crystallite size). Considering all the peaks [3] (2 $\theta$ in degree) in the X-ray diffractogram, the average crystallite (quantum dot) size has been assessed and found to be $9 \mathrm{~nm}$. Further, by analyzing the X-ray diffractogram with the help of ICDD (International Center Diffraction Data), it has been revealed that $\mathrm{ZnO}$ quantum dots are "wurtzite" in structure. HRTEM images of PVP film (Figure 3(a)) and $\mathrm{ZnO}$ quantum dots (Figure 3(b)) are shown in Figure 3. It is evident in the HRTEM image (Figure 3(b)) that $\mathrm{ZnO}$ crystallites (quantum dots) are circular in shape with sizes within 10 nm. Figure 3(c) shows the Scanning Electron Microscope (SEM) image of ZnO quantum dot surface.

$\mathrm{ZnO}$ sample sizes assessed from these three studies are well matching, which is a distinct advantage over earlier reports [2,3]. This matching occurs due to the formation of well uniformed and circular shaped quantum dots by using PVP matrix instead of PVA (polyvinyl alcohol) matrix [3]. All these characterizations infer that $\mathrm{ZnO}$ quantum dot sizes (diameter) are within $10 \mathrm{~nm}$.

\subsection{Ethanol Sensing}

To test ethanol sensing, $\mathrm{ZnO}$ sample is mounted on a two-probe assembly placed in sample holder into a silica tube which is inserted coaxially inside a tubular furnace. The furnace temperature is controlled within $\pm 1^{\circ} \mathrm{C}$ and the temperature variation over the length of the sample is found to be within $\sim \pm 1^{\circ} \mathrm{C}$. A known volume (parts per million, in short "ppm”) of ethanol is put with the help of a micro syringe into the closed silica tube. The electrical resistance of the sample is measured before and after exposure to ethanol using a Keithley System Electrometer (Model: 6514). The sensing response of $\mathrm{ZnO}$ quanum dots is determined at different operating temperatures in the range $220^{\circ} \mathrm{C}-360^{\circ} \mathrm{C}$ to various concentrations of 


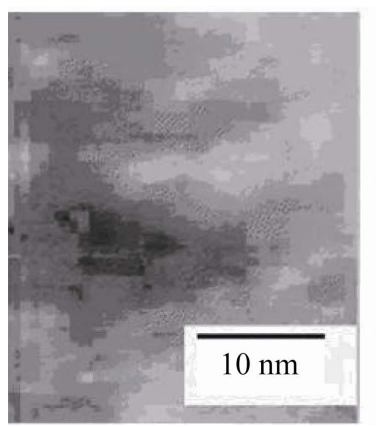

(a)

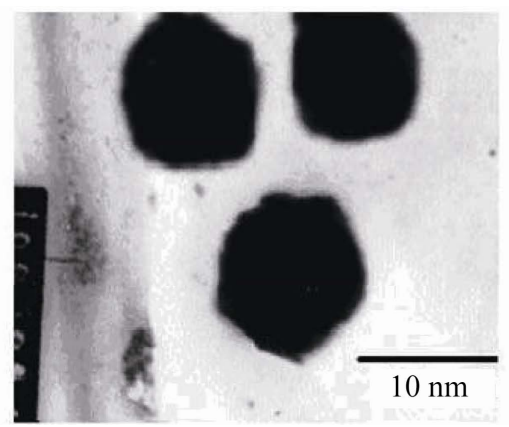

(b)

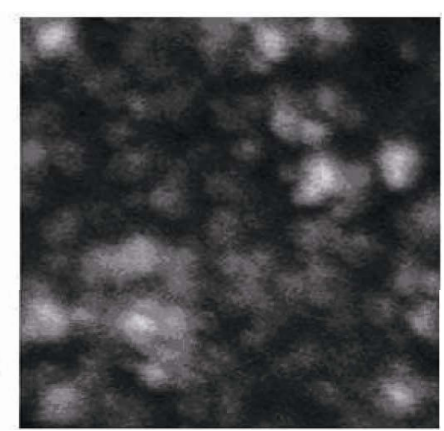

(c)

Figure 3. (a) HRTEM images of PVP; (b) HRTEM image of ZnO Q.D embedded in PVP; (c) SEM images of ZnO Q.D embedded in PVP.

ethanol $[9,10]$.

To study sensing [7-18], at first, $\mathrm{ZnO}$ quantum dot sample is heated in a chamber in air in the absence of test vapour when atmospheric oxygen is adsorbed chemically [18] on $\mathrm{ZnO}$ (as it is of $\mathrm{n}$ type specimen) surface. The adsorbed oxygen forms ionic species such as $\mathrm{O}^{2-}, \mathrm{O}_{2}^{-}$ and $\mathrm{O}^{-}$by the following reaction kinematics [18].

$$
\begin{gathered}
\mathrm{O}_{2} \text { (gas) } \leftrightarrow \mathrm{O}_{2} \text { (ads) } \\
\mathrm{O}_{2} \text { (ads) }+\mathrm{e}^{-} \leftrightarrow \mathrm{O}_{2}^{-} \text {(ads) } \\
\mathrm{O}_{2}^{-} \text {(ads) }+\mathrm{e}^{-} \leftrightarrow 2 \mathrm{O}^{-} \text {(ads) }
\end{gathered}
$$

The formation of $\mathrm{O}^{2-}$ species is also possible as follows

$$
\mathrm{O}^{-}(\mathrm{ads})+\mathrm{e}^{-} \leftrightarrow \mathrm{O}^{2-}
$$

These oxygen species desorbs upon exposure to ethanol vapour and results in decrease of $\mathrm{ZnO}$ quantum dot resistance $[8,9]$ as ethanol is reducing in nature. The desorption process occurs in one of the following ways depending on operating temperature [18]:

The reaction between ethanol vapour and ionic oxygen species can take place as follows [12,19].

$$
\mathrm{C}_{2} \mathrm{H}_{5} \mathrm{OH} \text { (gas) }+\mathrm{e}^{-} \leftrightarrow \mathrm{CH}_{3} \mathrm{COH}+\mathrm{H}_{2} \mathrm{O}+\mathrm{e}^{-}
$$

It is clear that ethanol reacts with chemi-adsorbed oxygen in $\mathrm{ZnO}$ quatum dot surface, inject charge carrier $\left(\mathrm{e}^{-}\right)$ to $\mathrm{ZnO}$ specimen and thereby reducing the sensor resistance. Thus, the "response" $[7,8]$ may be defined as $\left[\left(\left(R_{a}-R_{g}\right) / R_{a}\right) \times 100\right] \%$, where, $R_{a}$ is the $\mathrm{ZnO}$ quantum dot resistance in air and $R_{g}$ is the resistance upon exposure to ethanol. When the vapour is released by opening the enclosure of the sensing chamber, the reverse process takes place and $\mathrm{ZnO}$ quantum dot resistance regains its original value. Adsorption and desorption causing changes in sample resistance (that is gas sensing property) are absolutely surface phenomena
$[7,8,18]$. Due to large surface area (S/V ratio) $[5,13]$ of quantum dot, adsorption and desorption occur very fast resulting in sharp and fast changes in the resistance and thereby producing fast response with small changes in pre-heating temperature or concentration of vapour (ethanol).

Though there is no connection among the $\mathrm{ZnO}$ particles (Figure 3(b)) the charge carriers (that is electrons) can tunnel from one dot to another through the insulating PVP matrix of thickness around $9 \mathrm{~nm}$ [4].

While measuring ethanol response, at high temperature (at $250^{\circ} \mathrm{C}$ and above), PVP matrix (embedding $\mathrm{ZnO}$ quantum dots) tends to destroy (due to burning) but the electrical (i.e. sensing) property of $\mathrm{ZnO}$ quantum dot assembly is not at all affected [2] because charge carriers (electrons) can still tunnel from one dot to another dot through the burnt PVP layer as the layer is very thin (around $9 \mathrm{~nm}$ ) as shown in Figure 4.

Figure 5 represents the response characteristics as a function of operating temperatures for three different concentrations of 100, 300 and $500 \mathrm{ppm}$ of ethanol vapour. At low operating temperature around $230^{\circ} \mathrm{C}$, the response of $\mathrm{ZnO}$ quantum dot is restricted by slow chemical reaction while above $230^{\circ} \mathrm{C}$, the chemical reaction occurs very fast and efficiently resulting in higher

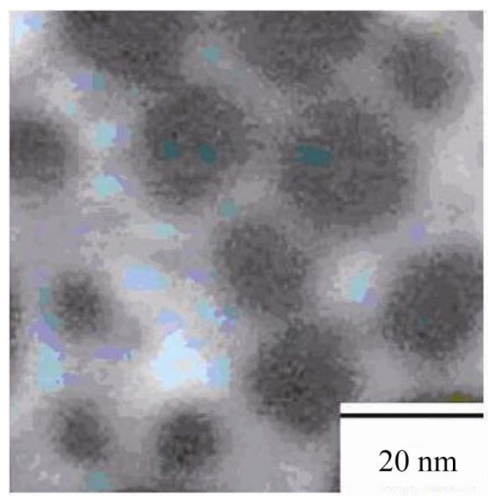

Figure 4. SEM images of $\mathrm{ZnO}$ Q.D after heating at $300^{\circ} \mathrm{C}$. 


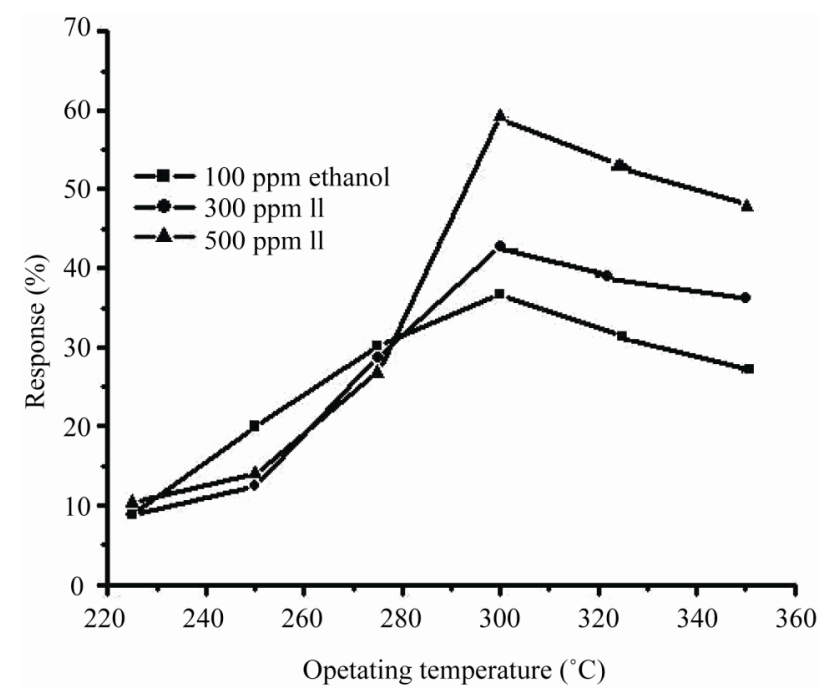

Figure 5. Response characteristics as a function of operating temperatures for three different concentrations.

response [9]. At $300^{\circ} \mathrm{C}$ the response is maximum. This is attributed to the availability of sufficient adsorbed ionic species of oxygen on $\mathrm{ZnO}$ surface which reacts most effectively and rapidly with ethanol molecules at this particular temperature [18] and produces large numbers of charge carriers $\left(\mathrm{e}^{-}\right)$resulting in rapid change (decrease) in sample resistance and hence higher is the response.At temperature higher than $300^{\circ} \mathrm{C}$, the mount of adsorbed (chemisorbed) oxygen is decreased with increasing temperature, but change in surface coverage in chemisorbed oxygen becomes smaller due to increased chemisorption rate of oxygen gas, leading to smaller response. A decrease in intrinsic sensor resistance in air (a larger electron concentration in air) with increasing operating temperature is another reason for lower response at temperatures higher than $300^{\circ} \mathrm{C}$. Figure 6 represents the transient response characteristics of $\mathrm{ZnO}$ quantum dot to ethanol concentration of 100,300 and $500 \mathrm{ppm}$ at $300^{\circ} \mathrm{C}$. Examining the graphs, it is revealed that the response time (time taken to reach $90 \%$ of saturation resistance $\left(\mathrm{R}_{\mathrm{g}}\right)$ on exposure to vapour) and recovery time (time taken to reach the $10 \%$ of the initial resistance $\left(\mathrm{R}_{\mathrm{a}}\right)$ on removal of the vapour) decrease with higher concentration. This is attributed [14] to the fact that higher concentration favors and accelerates the adsorption and desorption of the reaction products.

\section{Conclusions}

It is observed that the response of $\mathrm{ZnO}$ quantum dots embedded on PVP matrix is maximum at $300^{\circ} \mathrm{C}$, which occurs due to saturation of redox reaction between the ethanol vapour and the adsorbed oxygen species. $\mathrm{ZnO}$

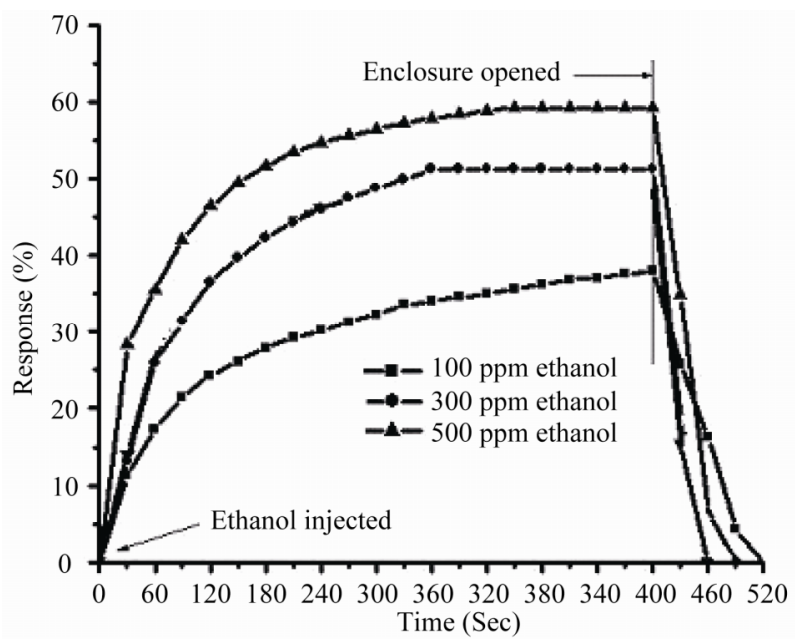

Figure 6. Transient response characterisctis of ZnO Q.D for diffrenet concentration of ethanol at $300^{\circ} \mathrm{C}$.

specimen posseses response even at very low concentration (100 ppm) of ethanol vapour. Response characteristic indicates that response time of $\mathrm{ZnO}$ quantum dots ethanol sensor is very less (as evident from Figure 6) which is much smaller than that of $\mathrm{ZnO}$ thin film ethanol sensor [18].

\section{Acknowledgements}

Authors thank Prof. A. Choudhury, Ex-Vice Chancellor, Gauhati University, Guwahati, Assam, India and Dr. D. K. Avasthi, Scientist H, IUAC, New Delhi, India for their suggestions and cooperation during the work. Author Also thank Mr S. Choudhury, Deputy General Manager Hindusthan Paper Corporation, Jaghiroad, Assam, India for providing his kind assistance to carry on the sensing experiment.

\section{References}

[1] S. S. Nath, M. Choudhury, D. Chakder, G. Gope and R. K. Nath, "Acetone Sensing Property of ZnO Quantum Dots Embedded on PVP," Sensors and Actuators B: Chemical, Vol. 148, No. 2, 2010, pp. 353-357. doi:10.1016/j.snb.2010.06.001

[2] S. S. Nath, D. Chakdar, G. Gope and D. K. Avasthi, "Effect of $100 \mathrm{MeV}$ Nickel Ions on Silica Coated ZnS Quantum Dots," Journal of Nanoelectronics and Optoelectronics, Vol. 3, No. 2, 2008, pp. 180-183. doi:10.1166/jno.2008.212

[3] S. S. Nath, D. Chakdar, G. Gope and D. K. Avasthi, "Novel Effect of Swift Heavy Ion on ZnO Quantum Dots Prepared by Quenching Method," Nanotrends-A Journal of Nanotechnology and Its Application, Vol. 3, 2008, pp. 1-10.

[4] S. S. Nath, D. Chakdar, G. Gope, J. Kakati, B. Kalita, A. 
Talukdar and D. K. Avasthi, "Green Luminescence of ZnS and ZnS: Cu Quantum Dots Embedded in Zeolite Matrix,” Journal of Applied Physics, Vol. 105, No. 9, 2009, pp. 094305-094309. doi:10.1063/1.3110767

[5] S. S. Nath, M. Choudhury, G. Gope and R. K. Nath, "PVA Embedded ZnO Quantum Dots for Methanol Sensing," Nanotrends-A Journal of Nanotechnology and Its Application, Vol. 8, 2010, pp. 1-4.

[6] D. Mohanta, S. S. Nath, A. Bordoloi, N. C. Mishra, S. K. Dolui and A. Choudhury, "Optical Absorption Study of 100-MeV Chlorine Ion Irradiated Hydroxyl Free ZnO Semiconductor Quantum Dots,” Journal of Applied Physics, Vol. 92, No. 12, 2002, pp. 7149-7152. doi:10.1063/1.1518751

[7] R. K. Nath and S. S. Nath, "Tin Dioxide Thin Film-Based Ethanol Sensor Prepared by Spray Pyrolysis,” Sensors and Materials, Vol. 21, 2009, pp. 95-104.

[8] P. P. Sayhay, S. Tewari and R. K. Nath, "Optical and Electrical Studies on Spray Deposited ZnO Thin Films," Crystal Research and Technology, Vol. 142, 2007, pp. 723-729.

[9] P. P. Sahay and R. K. Nath, “Al-Doped ZnO Thin Films as Methanol Sensors,” Sensors and Actuators B: Chemical, Vol. 134, No. 2, 2008, pp. 654-659. doi:10.1016/j.snb.2008.06.006

[10] Y. K. Fang and J. S. Lee, "A Tin Oxide Thin Film Sensor with High Ethanol Sensitivity,” Thin Solid Films, Vol. 169, No. 1, 1989, pp. 51-56. doi:10.1016/S0040-6090(89)80004-5

[11] S. Chakraborty, I. Mandal, I. Ray, S. Majumdar and A. Sen, "Improvement of Recovery Time of Nanostructured Tin Dioxide-Based Thick Film Gas Sensors through Surface Modification," Sensors and Actuators B: Chemical, Vol. 127, No. 2, 2007, pp. 554-558. doi:10.1016/j.snb.2007.05.005

[12] L. Peng T.-F. Xie, M. Yang, P. Wang, D. Xu, S. Pang and D.-J. Wang, "Light In- duced Enhancing Gas Sensitivity of Copper-Doped Zinc Oxide at Room Temperature," Sensors and Actuators B: Chemical, 2008, pp. 659-660.

[13] V. S. Vaishnava, P. D. Patelb and N. G. Patelc, "Indium Tin Oxide Thin Film Gas Sensors for Detection of Ethanol Vapours," Proceedings of the 4th International Workshop on Semiconductor Sensors (SGS 2004), Vol. 490, No. 1, Thin Solid Film, Sciencedirect, 21 October 2005, pp. 94-100.

[14] T. P. Hulser, H. Wiggers, F. E. Kruis and A. Lorke, "Nanostructured Gas Sensors and Electrical Characterization of Deposited $\mathrm{SnO}_{2}$ Nanoparticles in Ambient Gas Atmosphere," Sensors and Actuators B: Chemical, Vol. 109 , No. 1 , 2005, pp. 13-18. doi:10.1016/j.snb.2005.03.012

[15] S. M. Chou, L. G. Teoh, W. H. Lai, Y. H. Su and M. H. Hon, "ZnO: Al Thin Film Gas Sensor for Detection of Ethanol Vapor,” Sensors, Vol. 6, No. 10, 2006, pp. 14201427. doi: $10.3390 / \mathrm{s} 6101420$

[16] S. L. Bai, L. Y. Chen, P. C. Yang, R. X. Luo, A. F. Chen and C.-C. Liu, "Sn/In/Ti Nano- Composite Sensor for $\mathrm{CH}_{4}$ Detection," Sensors and Ac- tuators B: Chemical, Vol. 135, No. 1, 2008, pp. 1-6. doi:10.1016/j.snb.2008.06.051

[17] B. Bhooloka Rao, “Zinc Oxide Ceramic Semi-Conductor Gas Sensor for Ethanol Vapour,” Science Direct, Materials Chemistry and Physics, Vol. 64, No. 1, 2000, pp. 62-65.

[18] P. P. Sahay, S. Tewari, S. Jha and M. Shamsuddin, "Sprayed ZnO Thin Films for Ethanol Sensors," Journal of Materials Science, Vol. 40, No. 18, 2005, pp. 47914793. doi:10.1007/s10853-005-0519-9

[19] K. K. Makhija, Arabinda Ray, R. M. Patel, U. B. Trivedi and H. N. Kapse, "Indium Oxide Thin Film Based Ammonia Gas and Ethanol Vapour Sensor," Bulletin of Materials Science, Vol. 28, No. 1, 2005, pp. 9-17. doi:10.1007/BF02711165 